\title{
Rainfall Variability and Linear Trend Models on North-West Part of Bangladesh for the Last 40 Years
}

\author{
M. Anisur Rahman ", S. M. Mostafa Kamal, M. Maruf Billah \\ Department of Mathematics, Islamic University, Kushtia, Bangladesh
}

Email address:

anismathiu@yahoo.com (M. A. Rahman),kamaliubd@yahoo.com (S. M. M. Kamal), marufmath0317@gmail.com (M. M. Billah)

${ }^{*}$ Corresponding author

\section{To cite this article:}

M. Anisur Rahman, S. M. Mostafa Kamal, M. Maruf Billah. Rainfall Variability and Linear Trend Models on North-West Part of Bangladesh for the Last 40 Years. American Journal of Applied Mathematics. Vol. 4, No. 3, 2016, pp. 158-162. doi: 10.11648/j.ajam.20160403.16

Received: February 26, 2016; Accepted: May 13, 2016; Published: June 4, 2016

\begin{abstract}
Rainfall has been extensively considered as one of the initial point towards the apprehension of climate change courses. Bangladesh is recently experiencing climate change impact related to hazards like cyclone, rainfall, flood, draught etc. Climate variable like rainfall is the most important parameter which is linked with agricultural aspects too for this country. Most of the rain occurred during monsoon period in Bangladesh. This study investigates temporal variability of rainfall and liner trend models on the North-West part of Bangladesh over the period of 1975-2014 using data from the Bangladesh Meteorological Department. We computed and analyzed the linear trend models by using least square estimation. We estimated mean with standard deviation, cross-correlation and linear trends of annual and monsoon rainfall using MS Excel and SPSS v21. The variability of rainfall between the stations was measured by correlation test. The annual and monsoon rainfall has been found in decreasing trends in recent times. In some areas in the North-Western part of the country, the amount of annual and monsoon mean rainfall may be decreased abruptly comparing with average normal rainfall all over the country. The linear trend analysis of rainfall reveals a bit different trend for the last four decades. The observed data and linear trend line shows the decreasing trend of annual rainfall rate is $0.102 \mathrm{~mm}$ per year, whereas the decreasing trend of monsoon season rainfall rate is $0.080 \mathrm{~mm}$ per year. The time series statistical analysis of this study also provided the information about the correlation coefficients of rainfall among the selected five stations of the South-West region. The result of this study would hopefully help the planners and program managers to take necessary actions and to measure disaster management, agricultural production, drought mitigation, flood control etc.
\end{abstract}

Keywords: Variability, Linear Trend, Rainfall, Correlation, North-West, Bangladesh

\section{Introduction}

Climate change has created a new challenge to hamper development process throughout the world. It is widely acknowledged that the impacts of climate-change amplify unfavorable climatic and environmental situations, particularly for developing countries [1]. Now it is well recognized that poor people are more vulnerable and have less adaptive capacity to confront such changes [2]. Countries with lack of natural resources, poor infrastructures and unstable institutions have little capacity to adapt and are highly vulnerable [3].

These factors are intrinsically linked with those promoting sustainable development that aims to improve living conditions and access to resources. Therefore, development planning and strategies have an important role in strengthening the adaptive capacities of societies at various levels.

Bangladesh is situated in the tropical belt and it has a warm and humid climate in the summer and a dry and cool weather in the winter. Even though Bangladesh is a small country with a land size of $147570 \mathrm{~km}^{2}$, inter-regional climatic differences in this flat country is not minor. The Eastern and North-Eastern parts of the country are wet, whereas the central and northwestern parts are dry. The spatial and temporal distribution of temperature is region 
dependent. The North-West region has been experiencing recurrent below-average rainfall and thus lowering of ground water levels in aquifers leading to water crisis for household, industry and agriculture. Rainfall is an important cause for the population living. Irregular rainfall and its associated extreme events could have negative impacts on the ecosystem, agriculture, business, health and overall livelihoods of the general people. There are some regions in Bangladesh where every steps of agricultural activities from field preparation to harvesting of crops dependents on rainfall [4]. An earlier study conducted by Endo et al. (2015) reported that heavy rainfall index showed no clear trend, and was dominated by inter-annual and/or decadal variations [5].

Bangladesh is considered to be one of the top ten most vulnerable countries in the world due to adverse impacts of climate change. Vulnerabilities include but not limited to sea level rise, changing rainfall patterns, increase in intense precipitation events, changes in seasonality patterns, increase temperature and frequency of extreme climatic events like floods and cyclones $[6,7]$.

In Bangladesh, four distinct seasons can be recognized from a climatic point of view. These four seasons are: (i) Dry winter season (December to February); (ii) Pre- monsoon hot summer season (March to May); (iii) Rainy monsoon season (June to September); and (iv) Post monsoon autumn season (October to November). Climate of the north-western region, like rest of Bangladesh is characterized by extremely warm temperatures, low humidity and triviality seasonal variations in rainfall. In this region the monsoon climate substantially controls the life style of the peoples, especially under the social and economical conditions of agriculture dependent countries like Bangladesh. The study of rainfall variability helps in assessing drought and flood risk, relief and rehabilitation during extreme events, and finally local level contingency planning.

Bangladesh is one of the most flood prone countries in the world due to its geographic position. It is notable that, severe floods that occurred in the years 1974, 1984, 1987, 1988, 1998, 2004 and 2007 devastated the country greatly. Drought in the north-western part of the country has captured a growing concern in the more recent years. The country has experienced eight droughts of severe magnitude in the years 1973, 1977, 1979, 1982, 1989, 1992, 1994-1995 and 1999 [8, 9]. A better understanding of the rainfall pattern is important for formulating efficient resource management and climate change adaptation policies [10]. Bangladesh is situated at the interface of two different environments, with the Bay of Bengal to the South and Himalayas to the north. Due to its geographical position, Bangladesh experiences highest amount of country average monsoon and annual rainfall [11]. The rainfall of country is mainly governed by the activities of southwest summer monsoon. The summer monsoon is the main rainy season in Bangladesh which accounts for about 72 percent of the annual rainfall during summer monsoon season [12]. This study examines the outcome of an annual and monsoon seasonal trend analysis of a time series daily rainfall data from the five weather stations located in the
North-West part of Bangladesh.

\section{Data and Methods}

Data for this study have been extracted from the Bangladesh Meteorological Department (BMD). The BMD collects everyday surface data through weather stations situated all over Bangladesh. In this study, we used data from five weather stations from the North-Western part of Bangladesh. Considering long term availability of data and their suitability for objectives of the study data of five stations, namely Ishurdi, Rajshahi, Bogra, Rangpur and Dinajpur, have been selected for this study. The study period is January 1975 to December 2014. It is notable that, there were some missing data in some months. The missing rainfall values are computed by expectation maximization (EM) method. A full description of the EM algorithm can be found in McLach lan and Krishnan [13]. The collected data have been compiled, tabulated and analyzed by MS Excel and SPSSv21 (SPSS Inc., Shicago, IL, USA). Annual and monsoon average of rainfall for different stations are anticipated to analyze the variation and to estimate trend line for the period 1975 to 2014 . The monthly and yearly rainfall data have been obtained from daily rainfall data. Then, the mean, the standard deviation (SD) and the correlation coefficient among five stations have been estimated from yearly rainfall data.

We computed and analyzed the linear (1) trend models by using least square estimation.

$$
y=a x+b
$$

Where

$$
\mathrm{b}=\frac{\sum y_{i \cdot .} x_{i}^{2}-\sum x_{i \cdot \Sigma} x_{i} y_{i}}{n \cdot \sum x_{i}^{2}-\left(\sum x_{i}\right)^{2}}
$$

and

$$
\mathrm{a}=\frac{n \cdot \sum x_{i} y_{i}-\sum x_{i .} \sum y_{i .}}{n \cdot \sum x_{i}^{2}-\left(\sum x_{i}\right)^{2}}
$$

$x_{i}$ represents years in the time series considered $\left(x_{0}=0\right.$ for the year 1975, the first year in the time series considered), and $y_{i}$ represent the weather parameter considered (the mean annual or monsoon precipitation). All summations run through $i=0,1,2, \ldots \ldots .40$ i.e. a total of 40 years. (2) and (3) are the solutions to the normal equations associated with the system.

The linear fit, thus obtained determines the behavior of the concerned climatic factors over the indicated period. The parameter considered is Standard Deviation (SD), a commonly-used measure of accuracy of fitted time series values. SD is computed using the following formula:

$$
S D=\sqrt{\frac{\sum_{t=1}^{n}\left(y_{t}-\hat{y}_{t}\right)^{2}}{n}}
$$

Since the rainfall distribution by geographical variation is important, the cross correlationship between the stations for 
two data series has been estimated by using the following Pearson's correlation formula:

$$
\operatorname{Corr}\left(R_{f_{1}}, R_{f_{2}}\right)=\frac{\sum\left(R_{f_{1}}-\bar{R}_{f_{1}}\right)\left(R_{f_{2}}-\bar{R}_{f_{2}}\right)}{\sqrt{\sum\left(R_{f_{1}}-\bar{R}_{f_{1}}\right)^{2} \sum\left(R_{f_{2}}-\bar{R}_{f_{2}}\right)^{2}}}
$$

where $\bar{R}_{f_{1}}$ and $\bar{R}_{f_{2}}$ are the mean rainfall for the series $R_{f_{1}}$ and $R_{f_{2}}$.

\section{Results and Discussion}

The results of this study on the variability and trend of rainfall over the North-West part of Bangladesh have been analyzed and discussed. Time series data sets are used for this study. Annual and monsoon mean total rainfall over five stations of Bangladesh during the 40 years (1975-2014) are shown in Fig. 1 and Fig. 2. It has been observed that the amount of mean annual rainfall for different stations is found to be between $100 \mathrm{~mm}$ and $192 \mathrm{~mm}$ with SDs of $11 \mathrm{~mm}$ to 72 $\mathrm{mm}$; whereas, the mean monsoon rainfall amount for different stations ranges between $205 \mathrm{~mm}$ and $480 \mathrm{~mm}$ with SDs of $23 \mathrm{~mm}$ to $181 \mathrm{~mm}$. It is seen from analysis that the rainfall variability and trend of all stations of the study region are decreasing. The observed data and linear trend line shows the decreasing trend of annual rainfall of the North-West region rate is $0.102 \mathrm{~mm}$ per year, where as the decreasing trend of monsoon season rainfall rate is $0.080 \mathrm{~mm}$ per year. The annual rainfall decreasing trends of all stations are greater than from the monsoon rainfall of all stations.

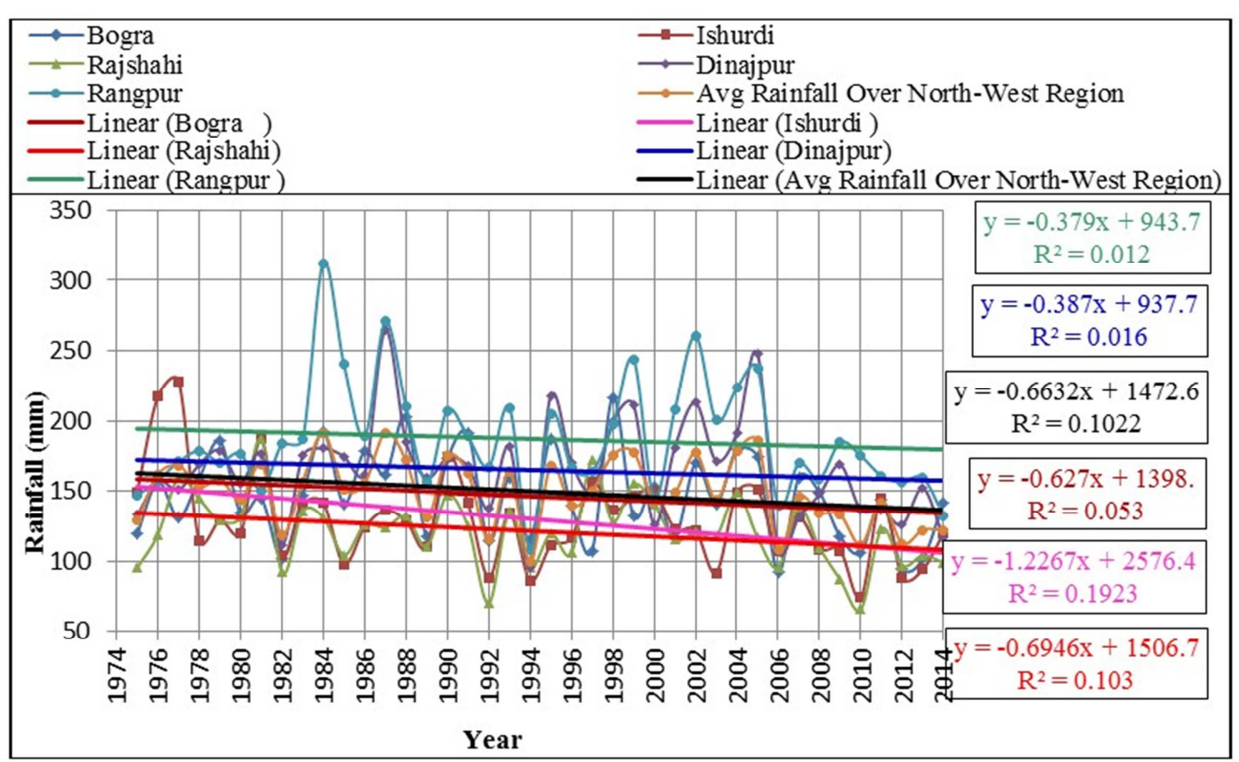

Fig. 1. Time series of annual mean rainfall at 5 stations during 1975 to 2014 .

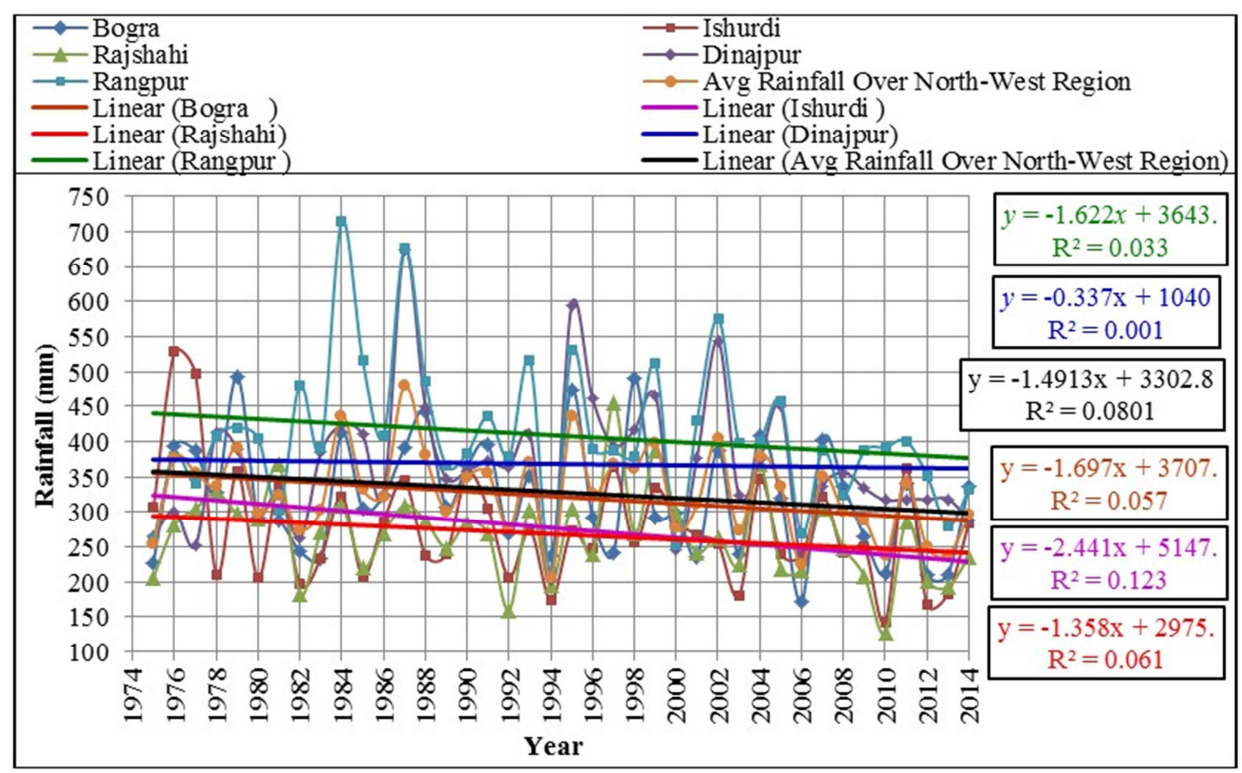

Fig. 2. Time series of monsoon mean rainfall at 5 stations during 1975 to 2014 . 
Among these stations, Ishurdi, Rajshahi and Bogra are found extremely decreasing trends. It is also analyzed that the decreasing trends of annual rainfall for Ishurdi, Rajshahi and Bogra were $0.192 \mathrm{~mm} /$ year, $0.103 \mathrm{~mm} /$ year and 0.053 $\mathrm{mm} /$ year respectively; and the decreasing trends of monsoon rainfall for those stations were $0.123 \mathrm{~mm} /$ year, 0.061 $\mathrm{mm} /$ year and $0.057 \mathrm{~mm} /$ year respectively. The estimated correlation coefficients for different stations under NorthWest part of Bangladesh have been captured in Table 1 and Table 2. The correlation coefficients yielded moderate and high level of correlations in the mean annual and monsoon rainfall for the selected stations.

Table 1. Correlation among annual mean rainfall of stations.

\begin{tabular}{llllll}
\hline Station & Ishudi & Rajshahi & Bogra & Rangpur & Dinajpur \\
\hline Ishurdi & 1.000 & $0.692^{* *}$ & $0.328^{*}$ & 0.082 & 0.223 \\
Rajshahi & & 1.000 & $0.418^{* *}$ & 0.201 & $0.344^{*}$ \\
Bogra & & & 1.000 & $0.491^{* *}$ & $0.581^{* *}$ \\
Rangpur & & & & 1.000 & $0.769^{* *}$ \\
Dinajpur & & & & & 1.000 \\
\hline
\end{tabular}

Note: Level of significance ${ }^{*} p<0.05,{ }^{* *} p<0.01$.

Table 2. Correlation among monsoon mean rainfall of stations.

\begin{tabular}{llllll}
\hline Station & Ishudi & Rajshahi & Bogra & Rangpur & Dinajpur \\
\hline Ishurdi & 1.000 & $0.600^{* *}$ & $0.487^{* *}$ & 0.102 & 0.053 \\
Rajshahi & & 1.000 & $0.422^{* *}$ & 0.247 & $0.327^{*}$ \\
Bogra & & & 1.000 & $0.455^{* *}$ & $0.489^{* *}$ \\
Rangpur & & & & 1.000 & $0.771^{* *}$ \\
Dinajpur & & & & & 1.000 \\
\hline
\end{tabular}

Note: Level of significance ${ }^{*} p<0.05,{ }^{* *} p<0.01$.

\section{Conclusion}

This study dealt with rainfall variability and linear trend for five rain gauge stations of North-Western part in Bangladesh for the period 1975-2014. We estimated the mean annual and monsoon rainfall with SD for this period. The findings reveal wide variations of rainfall for both annual and monsoon period. The findings from this study reveal that both the trends of annual and monsoon rainfall are decreased in recent years. The estimated correlation ratios between stations yielded moderate to high correlation for annual and monsoon period. The estimated mixed linear trend reveals decreasing of mean rainfall which implies that study region are tended towards drought. However, careful cautions are warranted to interpret these findings as the study used secondary data. Despite these limitations, the findings are appreciable and may provide valuable information for climate related studies such as water resources planning, agricultural productions and drought or flood contingency services. Thus it can be concluded that the rainfall is decreasing in recent years due to climate change and the sharp decreasing trend of rain over North-West region may be the key or one cause for decreasing trend of rainfall over the whole Bangladesh.

\section{Acknowledgment}

The authors are thankful to the Bangladesh Meteorological Department (BMD) for providing rain-gauge data and reference materials for preparing the article.

\section{References}

[1] McCarthy, J. J., O. Canziani, N. A. Leary, D. J. Dokken, and K. S. White, (2001), "Climate Change 2001: Impacts, Adaptation and Vulnerability", IPCC Working Group II, Cambridge University Press, Cambridge.

[2] Swart, R., J. Robinson, and S. Cohen, (2003),“Climate Change and Sustainable Development: Expanding the Options", Climate Policy 3(1), S19-S40

[3] Smit, B., and O. Pilifosova, (2001), "Adaptation to Climate Change in the Context of Sustainable Development and Equity", Chapter 18 in McCarthy, J. J., O. Canziani, N. A. Leary, D. J. Dokken, and K. S. White, "Climate Change 2001: Impacts, Adaptation, and Vulnerability - Contribution of Working Group II to the Third Assessment Report of the Intergovernmental Panel on Climate Change", Cambridge University Press, Cambridge, UK.

[4] Abdullah, H. M. and M. M. Rahman, (2015), "Initiating rain water harvest technology for climate change induced drought resilient agriculture: scopes and challenges in Bangladesh", Journal of Agriculture and Environment for International Development, Vol. 109, No. 2, P: 189-208.

[5] Endo, N., J. Matsumoto, T. Hayashi, T. Terao, F. Murata, M. Kiguchi, Y. Yamane and M. S. Alam, (2015), "Trends in Precipitation Characteristics in Bangladesh from 1950 to 2008”, SOLA, Vol. 11, P: 113-117.

[6] GOV. UK., (2011), "Climate: Observations, projections and impacts”, In: CENTRE, M. O. H. (ed.). UK.

[7] Smith, J. B., S. H. Schneider, M. Oppenheimer, G. W. Yohe, W. Hare, M. Mastranrea, D. Patwardhan, A. Burton, I. CorfeeMorlot and C. H., MAGADZA, (2009),“Assessing dangerous climate change through an update of the Intergovernmental Panel on Climate Change (IPCC)"reasons for concern". Proceedings of the National Academy of Sciences, Vol. 106: P. 4133-4137.

[8] Shahid S. and H. Behrawan, (2008), "Drought risk assessment in the western part of Bangladesh", Natural Hazards, Vol. 46, No. 3: P. 391-413.

[9] Shahid S. (2008), "Spatial and temporal characteristics of droughts in the western part of Bangladesh", Hydrological Processes, Vol. 22, No. 13: P. 2235-2247.

[10] Hasan, Z., S. Akter and M. Islam, (2014), "Climate Change and Trend of Rainfall in the South-East Part of Coastal Bangladesh", European scientific Journal, Vol. 10, No 2: P. 25-39.

[11] Devkota, L. P., (2006), "Rainfall over SAARC region with special focus on tele-connections and long range forecasting of Bangladesh monsoon rainfall, monsoon forecasting with a limited area numerical weather prediction system", Report No-19, Published by SAARC Meteorological Research Centre (SMRC), Dhaka, Bangladesh. 
[12] Ahasan, M. N., M. A. M. Chowdhury, and D. A. Quadir, (2008), "Few aspects of the flood disaster caused by heavy rainfall over Bangladesh", Proceedings of SAARC Seminar on Application of Weather and Climate Forecasts in the Socioeconomic Development and Disaster Mitigation, P.79-94.
[13] McLach lan, G. J. and T. Krishnan, (1997), "The EM Algorithm and Extensions", Wiley, New York City, New York. 